\title{
Reforma y revolución: la vía chilena al socialismo en la nueva izquierda intelectual argentina
}

\author{
Reform and revolution: the chilean road to socialism in argentine intellectual \\ new left
}

\author{
Mariano Zarowsky*
}

\begin{abstract}
Resumen: Según los balances clásicos la revisión del fenómeno peronista y el impacto de la revolución cubana fueron las dos grandes cuestiones que marcaron el debate y las identidades de la llamada nueva izquierda intelectual argentina en la década del sesenta. Ya entrados los años setenta, la experiencia en el gobierno de Chile de Salvador Allende (1970-1973) tuvo, sin embargo, una presencia destacada en las querellas de este medio intelectual. Este trabajo analiza el alcance, modulaciones y significaciones que tuvo esta presencia en tres revistas político-culturales de la época: Los Libros, Nuevos Aires, El Escarabajo de Oro.
\end{abstract}

Palabras clave: vía chilena al socialismo; intelectuales, nueva izquierda, Argentina, revistas político-culturales;

Abstract: According to the classic assessments both Peronism and the Cuban Revolution were the major issues shaping the evolution of the so-called New Left of the 1960s. In the next decade, Chile's socialist experience led by Salvador Allende (1970-1973) had also an important role in this process. This paper analyzes the impact of this experience on three politico-cultural publications of that time: Los Libros, Nuevos Aires, El Escarabajo de Oro.

Keywords: Chilean road to socialism; intellectuals; Argentine new left; politicalcultural reviews; socialism

Recibido: 5 abril 2016

Aceptado: 29 junio 2016 


\section{Introducción}

Según los testimonios y las investigaciones clásicas la revisión del fenómeno peronista y la revolución cubana fueron las dos grandes cuestiones que movilizaron en los años sesenta la emergencia, las identidades y los debates de lo que Oscar Terán denominó la nueva izquierda intelectual argentina. ${ }^{1}$ Poco abordados en su resonancia, los acontecimientos que giraron en torno a la llegada al poder de la Unidad Popular encabezada por Salvador Allende (1970-1973) tuvieron, no obstante, una presencia destacada en esta zona del campo intelectual y contribuyeron a reorientar algunos de sus debates, ya entrados los años setenta. En líneas generales, la victoria electoral de la UP "marcó una nueva temporalidad en el mapa político latinoamericano" " y alcanzó repercusiones a escala regional. A partir de entonces se potenciaron los debates acerca del camino más eficaz en la transición hacia el socialismo y la tensión "Reforma o Revolución" tomó nuevo vigor en la izquierda. El desarrollo de las instituciones académicas y políticas chilenas y la amplia recepción de numerosos intelectuales latinoamericanos exiliados que se había producido en los años previos $^{3}$ contribuyeron a que Chile se convierta en una extraordinaria caja de resonancia para estos debates. Y si bien la llamada "vía chilena al socialismo" podía resultar una experiencia incómoda o difícil de asimilar para la nueva izquierda intelectual argentina en el marco en el que se desenvolvía nuestro proceso político-cultural, ${ }^{4}$ el "Chile popular" no

* Argentino, Investigador Asistente del Consejo Nacional de Investigaciones Científicas y Técnicas (CONICET), Doctor en Ciencias Sociales y Magíster en Comunicación y Cultura (Universidad de Buenos Aires), es docente regular e investigador de la Facultad de Ciencias Sociales de la Universidad de Buenos Aires. El presente artículo es una reelaboración de la ponencia presentada en las VIII Jornadas de Historia de las Izquierdas organizadas por el Centro de Documentación e Investigación de la Cultura de Izquierdas (CEDINCI), Buenos Aires, noviembre de 2015.

1 Según Terán, la relectura del peronismo a partir de su caída provocó "efectos de recolocación de vastas consecuencias" y "constituyó uno de los rasgos político-culturales fundamentales del período". Terán, Oscar, Nuestros años sesenta, Buenos Aires, Siglo XXI, 2013 [1991], p. 65. En este aspecto ver también Altamirano, Carlos, Peronismo y cultura de izquierda, Buenos Aires, Siglo XXI, 2011 [2001]. Oficiando como impulso de esta recolocación la revolución cubana contribuyó según Claudia Gilman a configurar a escala latinoamericana una "nueva paideia para los intelectuales" que generó alineamientos y solidaridades específicos. Gilman, Claudia, Entre la pluma y el fusil, Buenos Aires, Siglo XXI, 2004, pp-28-29. Sobre el cruce de ambas cuestiones y su incidencia en el campo intelectual argentino de los años sesenta, ver también Sigal, Silvia, Intelectuales y poder en la década del sesenta, Buenos Aires, Punto Sur, 1991; Sarlo, Beatriz, La batalla de las ideas (1943-1973), Buenos Aires, Emecé, 2007 [2001] y Aricó, José, La cola del diablo. Itinerario de Gramsci en América Latina, Buenos Aires, Siglo XXI, 2005 [1988].

${ }^{2}$ Nercesián, Inés, "Chile durante los años setenta. Reforma o revolución. El MIR y la lectura de la situación latinoamericana”, en Waldo Ansaldi, Verónica Giordano (eds.), América Latina. Tiempo de violencias, Buenos Aires, Ariel, 2014, p. 245.

3 Véase Beigel, Fernanda (coord.), Autonomía y dependencia académica. Universidad e investigación científica en un circuito periférico. Chile y Argentina (1950-1980), Buenos Aires, Biblos, 2010.

${ }^{4}$ Sin restringirlo al campo intelectual, Tortti escribe que el concepto de nueva izquierda "nombra al conjunto de fueras sociales y políticas que, a lo largo de dos décadas, protagonizó un ciclo de movilización y radicalización que incluyó desde el estallido social espontáneo y la revuelta cultural hasta el accionar guerrillero, y desde la eclosión de movimientos urbanos de tipo insurreccional al surgimiento de direcciones clasistas en el movimiento obrero". Tortti, María Cristina, "La nueva izquierda argentina. La cuestión del peronismo y el tema de la revolución", en Tortti, María Cristina (directora), Chama, Mauricio, Celentano 
dejó de ocupar un lugar destacado en sus medios de debate y expresión. Como ocurrió con Cuba, aunque en menor escala y durante un tiempo más breve - pero no por eso menos intenso - a través de Chile, o mejor, de los límites y posibilidades que se atribuían al proyecto conducido por Salvador Allende, un conjunto de intelectuales discutió la Argentina, debatió sobre estrategias político-culturales y encontró un estímulo para problematizar su propia condición intelectual, encontrando en algunos casos un punto de apoyo para proyectar o replantear sus definiciones identitarias y teórico-políticas. En fin, del otro lado de la frontera de un país en el que, hacia 1970, se agudizaban los enfrentamientos sociales y se radicalizaban las alternativas, un frente electoral conducido por el Partido Comunista y el Partido Socialista, ambos de orientación marxista y de base obrera (sobre todo el primero) presentaba un programa en el que se proponía conducir un proceso de transición al socialismo partiendo de los marcos democráticos instituidos. La propuesta, refrendada por más del treinta y cinco por ciento de los votantes, obtuvo la primera minoría en las elecciones presidenciales el 4 de septiembre 1970. ¿Podía la novedad resultar indiferente en nuestro medio intelectual? ¿Qué presencia tuvo el proceso chileno en el debate de la llamada nueva izquierda intelectual argentina? ¿Cómo se lo interpretó y cómo se vincularon con éste sus intelectuales? ¿Qué efectos tuvo su emergencia y desenlace en sus discusiones y querellas? Si nuestras hipótesis son acertadas, ¿cómo pensar la relativa ausencia de la cuestión en las revisiones testimoniales y los balances historiográficos canónicos del período?

Nos proponemos acercarnos a estos interrogantes desde un prisma acotado pero que entendemos fructífero. Delimitamos un segmento de esa nueva izquierda intelectual, aquella que se expresó en tres revistas que supieron articular una orientación literaria con un perfil político-cultural: El Escarabajo de Oro, Nuevos Aires y Los Libros. ${ }^{5}$ Porque intentaron dirigirse a un destinatario más amplio que el público especializado o militante, porque entablaron explícita o implícitamente una conversación entre ellas - lo que amerita una lectura dialógica o, en otra modulación, en términos de campo- porque pretendieron asumirse como vehículos de renovación política e intelectual, la lectura cruzada de las tres publicaciones resulta un mirador productivo para abordar las cuestiones planteadas. En estas revistas encontraremos una serie de tópicos y tensiones que permiten dibujar el horizonte o, en términos de Raymond Williams, la estructura de sentir desde la que una parte de la nueva izquierda intelectual leyó el proceso chileno y sopesó su significación. Nos referimos al acercamiento a la vía chilena al socialismo desde el —en apariencia paradójico- "prisma cubano"; a la vivencia del triunfo de Allende como una interpelación a los intelectuales: un llamado a la acción que debía buscar modalidades específicas; a la puesta en circulación de lecturas que oscilaron entre la confianza en las fuerzas populares y el escepticismo frente a sus opciones estratégicas; por último, a la emergencia de la pregunta por lo que la experiencia chilena podía tener de inédito y singular para las

Adrián (co-directores), La nueva izquierda argentina (1955-1976). Socialismo, peronismo y revolución, Rosario, Prohistoria, 2014, pp. 17.

${ }^{5}$ Vale aclarar que la reconstrucción y el análisis que proponemos en este artículo no pretende agotar el espectro de la llamada nueva izquierda ni el de la franja de los intelectuales o formaciones culturales que participaron en ella; mucho menos sostener que la presencia del proceso chileno en el medio político-cultural argentino se limitó a este espacio. 
tradiciones de la izquierda y por aquello que podía encarnar y representar en las coordenadas en las que se desenvolvía la política argentina.

\section{Escritores e intelectuales frente al triunfo de la Unidad Popular}

En el modo en que en El Escarabajo de Oro (1961-1974), la revista dirigida por Abelardo Castillo, se asumió el triunfo de la Unidad Popular chilena tal vez se condensen algunos tópicos del debate que este proceso desencadenó en el mundo cultural de la nueva izquierda argentina. En sus páginas puede reconstruirse una estructura de sensibilidad que informa sobre el modo en que una franja intelectual fue interpelada por los acontecimientos que se sucedían del otro lado de la cordillera. Luego de una interrupción de casi un año, El Escarabajo de Oro volvía a la calle en noviembre de 1970 ( $\left.{ }^{\circ} 41\right)$, el mes que Salvador Allende asumía la presidencia de su país. ${ }^{6}$ Es sugerente notar cómo la presencia de los acontecimientos chilenos en la revista se anudaba con el modo en que se fundamentaba la adopción de un nuevo perfil para la publicación, que se autodefinía en torsión hacia nueva "etapa polémica": "[e]l número anterior inauguró, aunque algo intempestivamente, la década del 70. Hoy entramos de lleno en una especie de segunda época", anunciaba el editorial del número 42 (abril de 1971, p. 2). Luego de adelantar la presencia "provocativa" de textos de Ernesto Sábato, Julio Cortázar y Marta Lynch, los editores de El Escarabajo anotaban:

No ya para la derecha, para buena parte de la izquierda, CHILE, hoy, es más que una paradoja política en una encrucijada. La posibilidad de un nuevo camino para el socialismo, si se lo mira con simpatía, o un zarnazo [sic] de las llamadas teorías reformistas del comunismo. EL ESCARABAJO DE ORO estuvo en Chile los días tumultosos y festivos en los que Allende asumió el gobierno. Lo que vimos, en pág. 10. (p. 2).

Además de un dilema político — ¿ilusión reformista o revolución? - Chile representaba la ocasión para que El Escarabajo ensayara formas de involucramiento político sin perder su perfil y su especificidad. En polémica con aquellos que anunciaban la futilidad de todo esfuerzo literario se afirmaba que lo que no cambiaría de la publicación era que estaba hecha por hombres que, "además de jugarse por sus ideas", defendían la "literatura como creación". Este era su origen y su "irreversible fundamento" (p. 2). De allí la necesidad de buscar formas adecuadas de intervención.

En la disposición gráfica del número se puede leer el marco de coordenadas con las que El Escarabajo de Oro interpretaba el proceso chileno. En primer lugar, a partir de la

\footnotetext{
${ }^{6}$ En "La literatura como poder", El Escarabajo de Oro, n ${ }^{\circ}$, abril de 1971, p. 2, Liliana Heker situaba a la revista en una serie de debates que atravesaban entonces el campo literario: El Escarabajo se asumía en oposición frente a quienes asumían la crítica literaria con pretensión científica tanto como frente a los partidarios del abandono de la literatura en función de la acción política.

${ }^{7}$ Sobre el proyecto editorial y el perfil intelectual de El Escarabajo de Oro entre la creación literaria, el compromiso sartreano y su apoyo a la revolución cubana, ver Calabrese, Elisa, "Las revistas de Abelardo Castillo. Un proyecto cultural alternativo", en Revista CELEHIS. Tomo monográfico: Revista sobre revistas, año 14/15, n $17,2005 / 2006$, pp. 39-58.
} 
jerarquía de temas: en la tapa del número no se mencionaba la nota sobre Chile pero sí la publicación de una carta del Che Guevara al escritor Ernesto Sábato (p. 3). Allí el líder guerrillero hacía gala del carácter espontáneo y creativo de su accionar revolucionario y arrojaba una serie de proposiciones contra la actividad intelectual. ${ }^{8}$ Es sugestivo notar en la crónica sobre Chile se establecía una continuidad con la carta y las fotos del Che y, metonímicamente, del proceso chileno con la revolución cubana: la tipografía del título ("Acá Chile. Los caminos del socialismo") rodeaba una imagen que - ipara sorpresa del lector? - no era de Salvador Allende ni de las movilizaciones que se dieron en ocasión de su asunción, sino del monumento al Che en... Santiago de Chile. Allí el guerrillero de bronce vestido de fajina llevaba su fusil en alto.

La crónica del enviado especial al país andino, Amílcar Romero, da cuenta, sin embargo, de una lectura compleja y abierta de la situación, donde se anudaban, como dijimos, reflexiones político-estratégicas con aquellas que tematizaban la cuestión intelectual. En primera instancia ya desde el deíctico del título ("Acá Chile”) se construía la imagen de un enunciador que subrayaba como valor su voluntad y capacidad de participación directa en los acontecimientos. Garantía del "estar ahí" que anunciaba el editorial, a través de la crónica El Escarabajo encontraba un medio de intervención política y una forma específicamente literaria: abundan en el relato la utilización de indicadores de tiempo y espacio, descripciones detalladas de los sonidos y colores de los festejos, referencias a diálogos bajo la forma del discurso directo e indirecto que ponían en escena la presencia de la revista en los acontecimientos que acercaba al lector. Respecto a esta imagen de sí misma, es elocuente que Romero transcribiera la conversación que había tenido con "profesores" de la Universidad de Chile y de la Universidad Católica, quienes le habían preguntado, mientras elaboraban frenéticamente planes para el verano (Romero enumeraba: ayudar en los trabajos del campo, participar en las campañas de alfabetización, crear periódicos locales, editar libros por intermedio de las universidades, crear una revista latinoamericana) si "en la Argentina los intelectuales todavía seguían discutiendo en los cafés". No obstante, el cronista ofrecía una mirada analítica que evaluaba la naturaleza de la situación, su potencia, sus tensiones y posibles dificultades: si la burguesía iba a o no a reaccionar frente al gobierno; si el PCCh radicalizaría o frenaría la movilización popular; si las fuerzas armadas se inclinarían al golpe y si las fuerzas populares podrían disuadirlas, eran algunos de los interrogantes planteados. En fin, la crónica de Romero combinaba cierta fascinación con el proceso con una prudente distancia analítica: "Cualquier cosa puede pasar", concluía (p. 11). ${ }^{9}$

Nuevos Aires (1970-1973), la revista dirigida por Vicente Batista y Mario Goloboff, dedicó de manera íntegra el editorial de su tercer número (diciembre de 1970-enero febrero de 1971) al triunfo de la Unidad Popular. ${ }^{10}$ En un eje sintáctico, esta presencia de la

\footnotetext{
${ }^{8}$ En su visión la revolución cubana se había hecho sin una teoría previa, puesto que sus líderes habían caminado "mucho más rápido que su ideología anterior". Guevara la definía como "la más genuina creación de la improvisación" (p. 3).

${ }^{9}$ Seguía la nota de Romero una serie de poemas. De Mahfud Massis, "Canto y lucero para las mujeres de Chile" y otro de Roberto Fernández Retamar: "Madrigal".

${ }^{10}$ Nuevos Aires fue dirigida por Vicente Battista y Mario Goboloff, provenientes de El Escarabajo de Oro. Salieron once números entre 1970 y 1973. En líneas generales, la revista recogió los debates sobre el lugar del
} 
experiencia chilena cobra dimensión y relieve si se la coloca en una serie junto a las otras "grandes cuestiones" y acontecimientos que ocuparon a la publicación literaria en su breve vida (Cuba y los intelectuales, el caso Padilla, las relaciones entre vanguardias políticas y vanguardias estéticas, la masacre de Trelew, el triunfo de Héctor Cámpora, etc.). En un eje paradigmático, la actitud de Nuevos Aires frente al proceso chileno puede leerse de manera dual, esto es, como un pronunciamiento político-ideológico tanto como un modo de diferenciación en el sistema de las revistas literarias y en el campo intelectual.

En efecto, en contraposición a El Escarabajo de Oro - y, como veremos, también a Los Libros - Nuevos Aires planteaba de entrada y sin claroscuros su cautela - por no decir escepticismo - frente al triunfo de Allende. Según los editores, el 4 de septiembre de 1970 "las posiciones reformistas en América Latina" habían recibido de Chile un "colosal impulso". "Si bien admitían que la Unidad Popular presentaba un programa revolucionario, se preguntaban si su llegada al gobierno equivalía a la llegada al poder. En su discurso de asunción, haciendo uso de una conocida cita de Frederic Engels, Allende se había manifestado confiado en que el apoyo popular expresado en una mayoría electoral permitía iniciar un camino inédito en la historia mundial de las luchas anticapitalistas. Con cierta desconfianza, Nuevos Aires se interrogaba si este tipo de supremacía bastaría para quebrar la resistencia que ofrecerían las clases poseedoras hipotéticamente despojadas. ¿Qué papel jugarían ante una agudización del conflicto las fuerzas internacionales? ¿Qué posición tomaría la URSS? Y sobre todo, ¿cuál sería la actitud de las fuerzas armadas? La idea de su neutralidad en la política chilena jugaba — en la perspectiva de los editores - un importante papel en la visión ingenua que sobre el cambio tenían algunos sectores de la izquierda. ¿Acaso esta aparente prescindencia no era resultado más bien de que su intervenciones habían sido más efectivas - -y, por ende, más durables - de lo que habían sido las intervenciones de sus pares en el resto de los países de América Latina? (p. 4). Así Nuevos Aires manifestaba su asombro frente a lo que consideraba era una falta absoluta de reflexiones y de propuestas en todo el arco de los medios de la izquierda chilena acerca de las modalidades que adoptaría la defensa del gobierno electo en caso de una agresión efectiva. En su perspectiva, esto se explicaba porque una larga "tradición parlamentaria" y "reformista" "embotaba" a las fuerzas hegemónicas de la Unidad Popular y les impedía darse bases concretas de sustentación en el aparato estatal. Evidentemente, junto a la discusión doctrinaria se jugaba otra partida: a través de Chile Nuevos Aires tamizaban opciones estratégicas, lecturas del presente argentino y, especialmente, una interrogación sobre su estatuto y función intelectual. "Nuestra especulación no es académica —se

intelectual y la relaciones entre artistas, intelectuales y revolución, entre vanguardia estética y vanguardia política. Al respecto ver de Diego, José Luis, ¿Quién de Nosotros escribirá el Facundo? Intelectuales y escritores en Argentina (1970-1986), La Plata, ediciones Al Margen, 2007 [2004].

${ }^{11}$ En palabras de los editores, la victoria electoral de la Unidad Popular había reavivado "la pálida alternativa que esa salida ofrecía ante la acción insurreccional de las vanguardias por desbrozar en sus países el camino de la liberación social y nacional" (p. 3). Si los movimientos revolucionarios guerrilleros habían sufrido derrotas recientes en Colombia, Venezuela, Perú y Bolivia, las variantes "recambistas" parecían florecen en la parte Sur de América, con Juan Velasco Alvarado en Perú y Juan José Torres, en Bolivia. Con el vuelco chileno se habría demostrado globalmente, para aquella concepción, que el camino de las masas al poder no pasaría por la "acción frontal contra el sistema sino por el sostenido ensanchamiento de brechas democráticas en su interior." (p. 3). Nuevos Aires, "Las otras caras de 'La Moneda"” (Editorial), pp. 3-6. 
explicitaba-: nos dirigimos a la intelectualidad argentina $\mathrm{y}$, de ella, a un sector bastante definido al que debemos confesar certezas y dudas" (El subrayado me pertenece). El Chile popular, en suma, asumía una significación que trascendía sus fronteras:

Es claro que lo acontecido y lo que sobrevenga asume para nosotros cualidades significativas. Chile es hoy el nudo en el que puede definirse por mucho tiempo el pulseo entre dos concepciones sobre el camino que conduce al cambio. Cualquiera sea el anecdotario que vele lo esencial, la experiencia latinoamericana ha demostrado que una postura lleva a la parálisis, a la desilusión, a la frustración de posibilidades. La otra, en permanente proceso de elaboración teórica y práctica (...) con lo que pueda incluir de pesimista y de alerta, tiene presente la dificultad para vencerla, la oposición para superarla. En todo caso es preferible el error por exceso de vigilia a dormir otro fatigoso 'Yo acuso' de Neruda (p. 6).

La mención final a Pablo Neruda hacía referencia a la carta pública de protesta contra la feroz oleada represiva que el poeta le había dirigido en noviembre de 1947 al entonces presidente González Videla (1946-1952), su ex aliado en el Frente Popular. ${ }^{12}$ La ironía no sólo apuntaba a lo que se caracterizaba como una ingenuidad de parte de la estrategia frentista, sino a la idea de literatura y a la propia imagen de intelectual que encarnaba el entonces prestigioso poeta comunista. Adquiere significación si se la lee en el marco del dossier que en el mismo número Nuevos Aires le dedicaba a la literatura chilena, donde publicaba una serie de poetas y narradores "malditos", como Pablo de Rokha, Gonzalo Rojas, Enrique Lihn y Fernando Alegría. Esta selección marcaba una opción estética y política diferenciada frente a la figura consagrada de Neruda. La contraposición entre los "dos Pablos", el Neruda exitoso y el "perdedor" de Rokha funcionaba de manera explícita como una analogía respecto al proceso popular: Rokha encarnaba una intransigencia con el orden cultural y político que debía ser total y violenta, aun si para ello tenía que pagar con la marginación o la propia vida. ${ }^{13}$

También el triunfo de la Unidad Popular generó marcadas expectativas en la revista Los Libros, que le dedicó al acontecimiento un lugar por demás destacado, más o menos en simultáneo al El Escarabajo de Oro y Nuevos Aires. Fundada por Héctor Schmucler en 1969, la publicación se había presentado en ruptura con las formas y los fundamentos que asumían las revistas literarias y culturales. ${ }^{14}$ En este punto, no es exagerado afirmar que el

\footnotetext{
${ }^{12}$ A los pocos meses de asumir como presidente, González Videla se volvió contra sus aliados comunistas en el gobierno, promoviendo una feroz represión contra ellos.

${ }^{13}$ La semblanza de Julio Huasi sobre Pablo de Rokha que abría la serie mezclaba recursos de la crónica periodística y la ficción al estilo del "nuevo periodismo" con la crítica literaria. Construía una imagen "maldita" del poeta chileno fallecido en 1968, una figura marginal y crítica del establishment literario local, aun de sus versiones de izquierda. Ningún fragmento de Rokha (sumido en la pobreza se había suicidado luego de perder un hijo) podía integrar el orden existente, escribía Huasi: sólo podrían ser rescatados por la "nueva cultura latinoamericana que insiste en anunciarse entre los nuevos fuegos continentales, incinerando arcaicas aduanas de admisión, "reaccionarias" o "democráticas", de poesías y poetas" (p. 10).

14 Proponiendo una "desacralización" de la propia institución literaria, una utilización rigurosa de herramientas teórico-metodológicas provenientes de las modernas ciencias sociales y de los lenguajes, la revista aspiraba a ser un instrumento para descifrar el carácter histórico-social de la literatura y la ideología subyacente en el pensamiento y los textos culturales “donde el mundo se escribe así mismo". Los Libros hacía
} 
triunfo electoral de la Unidad Popular funcionó como un catalizador que contribuyó a precipitar y a dar forma un programa de intervención. "La experiencia política chilena de estos días" abría "un mundo de problemas y de perspectivas de gran interés para América Latina. Los Libros ha sentido un deber participar de esos acontecimientos", afirmaba el editorial del número 13 de noviembre de 1970. Se anunciaba así lo que sería el contenido del siguiente número y se exhibía lo que se vivía como un llamado para involucrarse en los acontecimientos. En ese mismo momento, se anticipaba, el secretario de redacción de Los Libros, Santiago Funes, se encontraba como enviado especial en Chile trabajando "junto a un grupo de especialistas" dirigidos por Armand Mattelart en el material que integraría el número siguiente (p. 3).

Mirado retrospectivamente, el número especial sobre Chile (que finalmente no fue el 14 sino el 15-16, de enero- febrero de 1971) inauguró una nueva etapa en la publicación: fue el primero de una serie dedicada a procesos políticos latinoamericanos. La expectativa que abrió el triunfo de la Unidad Popular fue notable. Chile ofrecía la posibilidad de renovar y ampliar la discusión sobre las opciones político-estratégicas en el camino hacia el socialismo, al mismo tiempo que un espacio potencial para la intervención intelectual. Para ser más precisos, para Los Libros Chile tal vez fuera un mirador donde se proyectara una posición anhelada: unas ciencias sociales profesionalizadas y abiertas a un marxismo renovado se configuraban y pensaban en estrecha relación con el proceso de cambio. La vía chilena al socialismo se presentaba en este primer momento, a diferencia de lo que ocurría entonces en Nuevos Aires o de lo que posteriormente sucedería en la propia revista luego de la salida de Schmucler, como un vehículo de interrogación y experimentación que desataba expectativas poderosas:

Chile ocupa desde noviembre del año pasado un lugar privilegiado en el interés de la historia contemporánea. Al asumir el mando el presidente Allende, se reordenó el cuadro de la situación latinoamericana y la expectativa interesó a todo el mundo. El proceso político se ha reestructurado de tal manera en el planeta, que el menor movimiento de uno de los elementos pone en vibración a toda la compleja estructura internacional. El cambio chileno remitió de inmediato a las grandes capitales: desde Washington a Pekín. Los movimientos liberadores que con distintos matices se desarrollaron en los países latinoamericanos, adquirieron nueva significación. En la Argentina, todas las fuerzas se pusieron en tensión: no es poca monta estar unida a Chile por dos mil kilómetros de límites (...). Fase abierta de un proceso inédito en América Latina, el acceso al poder formal por parte de la Unidad Popular, comienza a verificar su importancia, sus dificultades, su potencia. Hacia esta última, como

de esta posición crítica un modo de intervención política. La latinoamericanización de la revista coincidía con la asunción de formas cada vez más explícitas de involucramiento en los acontecimientos políticos y esta politización se asumía delimitando una zona específica de trabajo e indagación: la politicidad de la cultura. Su definición, paradójicamente, ensanchaba su alcance hasta límites insospechados. Sobre el proyecto crítico y político cultural de Los Libros véase de Diego, José Luis, ¿Quién de Nosotros escribirá el Facundo? Intelectuales y escritores en Argentina (1970-1986), op. cit. y Panesi, Jorge "La crítica argentina y el discurso de la dependencia", en Críticas, Buenos Aires, Norma, 2000 [1985], pp. 17-48. 
problema, hemos tratado de aproximar los textos que se publican (p. 3. El subrayado es mío).

En términos del debate político-estratégico, la expectativa de Los Libros se expresaba en la diversidad de materiales que componían este dossier. En este se disponía, lejos de una visión monolítica, una variedad de asuntos que hacían a las cuestiones y los desafíos que debía enfrentar el movimiento popular chileno: la reforma agraria, el problema de la vivienda y de los asentamientos; la nacionalización del cobre, la actitud de los escritores y el lugar de las políticas culturales, el rol de los medios de comunicación, etc. Se trataba de un proceso "inédito" y "abierto" cuya resolución no estaba prefigurada de antemano. De conjunto, las notas desplegaban una actitud analítica tendiente a leer la coyuntura y a identificar su potencial -en términos del desarrollo de una perspectiva socialista y revolucionaria - tanto como sus límites y dificultades. De allí que fueran temas de la reflexión crítica la actitud del Partido Comunista Chileno, la posición de las fuerzas armadas, las restricciones estructurales de la economía, las asimetrías ideológicas, etc. ${ }^{15}$ En términos generales, se señalaba la heterogeneidad de los actores y la complejidad de un proceso que escapaba a las clasificaciones a priori y a los preconceptos. En esta línea expectante, son elocuentes una serie de trabajos: el del James Petras, por ejemplo, quien identificaba estadísticamente la composición obrera del voto a la UP y afirmaba la existencia de una base sólida para que los partidos marxistas que la componían implementaran "cambios anticapitalistas radicales" (p. 13). En una línea convergente se expresaban Fermin Amina en su reseña sobre La democracia chilena de Norbert Lechner (pp. 14 y 56), donde afirmaba que la novedad de la UP respecto de otras experiencias latinoamericanas era que la "tentativa nacional populista" era hegemonizada por partidos marxistas, de ahí su potencial, y José Nun, en su sugerente comentario del libro de Alain Joxe, Las fuerzas armadas en el sistema político de Chile (pp. 49-50). Nun discutía a quienes suponían a priori que el gobierno de la UP encontraría límites infranqueables, cuando arrojaban la preguntaban sobre si las fuerzas armadas clausurarían el proceso con un golpe de Estado. Estas preguntas para Nun resultaban "demasiado abstractas", y lo eran "tanto como sostener de entrada" que el gobierno de Allende estaba "condenado al fracaso". Los militares no constituían un bloque monolítico ni eran un sector externo a la sociedad, por lo que la tarea política pasaba por objetivar el campo de las alianzas y de las relaciones de fuerzas en tensión. El horizonte de lo posible, aun si se evaluaba con rigor la estrategia de la Unidad Popular, ${ }^{16}$ parecía abierto a la voluntad y a la acción política. Es

\footnotetext{
${ }^{15}$ Las cuestiones culturales en la transición socialista ocupaban un lugar destacado en el dossier, con la publicación de artículos de Ariel Dorfman, Armand Mattelart y del manifiesto del Taller de Escritores de la Unidad Popular: "por la creación de una cultura nacional y popular". Al respecto véase Zarowsky, Mariano, Del laboratorio chileno a la comunicación-mundo. Un itinerario intelectual de Armand Mattelart, Buenos Aires, Biblos, 2013; Zarowsky, Mariano, "De Los Libros a Comunicación y cultura. Praxis editorialista y proyecto intelectual en el itinerario de Héctor Schmucler”, en La trama de la Comunicación, Vol. 20, n 1 , 2016.

${ }^{16}$ Siguiendo a Stanley Moore (Three Tactics, Nueva York, Monthly Review Press, 1963) Nun sostenía que debían distinguirse las tesis del "reformismo relativo" y las del "reformismo absoluto". Mientras que éste sostenía que la transformación podía iniciarse y también concluirse pacíficamente, el segundo sostenía que en determinadas circunstancias la transición al socialismo podía iniciarse de forma pacífica, pero que en algún
} 
elocuente que Nun concluyera su argumentación citando un conocido pasaje de la crítica de Antonio Gramsci a Nicolai Bujarin: "En realidad, sólo puede preverse científicamente la lucha, pero no los momentos concretos de esta lucha, que no pueden ser sino el resultado de fuerzas en oposición y en continuo movimiento, fuerzas que nunca pueden ser reducidas a cantidades fijas, pues en ellas la cantidad se vuelve continuamente calidad".

Al igual que en El Escarabajo de Oro y en Nuevos Aires, también en Los Libros Chile oficiaba como motor para problematizar la condición intelectual y para explorar formas de involucrarse en los acontecimientos. Es significativo que en el editorial que presentaba el contenido del número especial se destacara el largo reportaje que el enviado especial de Los Libros había hecho junto a un equipo de colaboradores a los pobladores del "campamento Che Guevara", un asentamiento en Santiago de Chile orientado por militantes del Partido Socialista. Según los términos del editorial, se trataba de "dar testimonio" de "una experiencia de consecuencias imprevisibles". Los Libros anunciaba así la ampliación de su registro y un desplazamiento en su perfil: las reseñas de libros se acompañarían a partir de entonces de panoramas informativos y analíticos de problemas vinculados "al destino de las naciones latinoamericanas"; esta sería la manera de asumir "la responsabilidad ahora insoslayable con la transformación que los pueblos del continente parecen haber tomado en sus manos", se afirmaba. ${ }^{17}$ En fin, "si es cierto que el gobierno de la Unidad Popular abre la posibilidad de una transición hacia el socialismo realizada en condiciones inéditas en América Latina" — se concluía en la bajada de presentación de reportaje-, experiencias como la que allí se testimoniaban podían "constituirse en uno de los apoyos materiales indispensables para asegurar su concreción”.

\section{3: la caída de Allende y las "lecciones" de Chile}

Ni Nuevos Aires ni El Escarabajo de Oro volvieron a ocuparse del proceso chileno en los dos años siguientes. Un recorrido por las páginas de las revistas permite observar que otras cuestiones ocuparon sus editoriales o sus páginas propiamente "políticas": el caso Padilla, el GAN y, sobre todo, las alternativas y perspectivas que abría la posibilidad del retorno del peronismo al poder. El último número de Nuevos Aires $\left(\mathrm{n}^{\circ} 11\right)$ salió en agosto de 1973,

momento del proceso el aparato de Estado y sus fuerzas armadas deberían ser destruidos. Las tesis que estaban sometidas a prueba en el caso chileno no eran las tesis del reformismo absoluto, sino las del relativo. En este sentido Nun advertía que era discutible la pertinencia de la cita de la Crítica de un esbozo para el Programa de Erfurt (1891) de Engels que Allende había hecho en su discurso de asunción. Esta rezaba que podía "concebirse la evolución pacífica de la vieja sociedad hacia la nueva en los países donde la representación popular concentra en ella todo el poder, donde, de acurdo con la Constitución, se puede hacer lo que se desee, desde el momento en que se tiene tras de sí a la mayoría de la nación”.

${ }^{17}$ Mezcla de reportaje periodístico y "encuesta obrera", la entrevista a los pobladores del campamento "Che Guevara" ponía en juego técnicas de registro que acercaba a los cronistas con los protagonistas: se subrayaba la presencia en el terreno como forma de intervención y se aspiraba a una forma de mediación que buscaba tanto dar testimonio de una faceta no conocida del proceso como ensayar un análisis que, asumiendo por momentos una inflexión pedagógica frente a los entrevistados, indagaba en sus contradicciones y límites. La conversación giraba en torno a una serie de temas: la organización en milicias de autodefensa, las concepciones sobre la justicia popular, las dificultades de la organización cotidiana, la diferenciación con la línea estratégica y el modo de trabajo del PCCh, entre otras cuestiones. 
poco antes del golpe de Estado de Pinochet del 11 de septiembre, por lo que el balance de su desenlace tampoco pudo tener un lugar en sus páginas. Sí lo tuvo en El Escarabajo de Oro, que volvió a ocuparse de Chile en sus números 47 (diciembre de 1973-febrero de 1974) y 48 (julio-septiembre de 1974). En éste último El Escarabajo publicó a una serie de poetas chilenos - Nicanor Parra, Luis de Paola, Víctor Jara, Ivan Egüez - a modo de homenaje al Chile popular. Como en buena parte de las publicaciones de la época vinculadas al espacio de la nueva izquierda, ${ }^{18}$ el proceso chileno era significado ahora desde coordenadas más estrechamente vinculadas a la dinámica de la política argentina; o mejor — puesto que desde el comienzo el acercamiento a los acontecimientos al otro lado de la cordillera no podía hacerse sino mediado por una lectura en clave local- el prisma nacional se hacía ahora más explícito: a partir de septiembre de 1973 interpretar la vía chilena al socialismo y ensayar explicaciones de la caída de la Allende se volvía un modo de leer la Argentina y una ocasión para debatir sobre sus alternativas estratégicas; más precisamente, sobre los avatares de la relación entre Perón, el ala juvenil radicalizada de su movimiento y las organizaciones armadas. En el editorial del número 47 de El Escarabajo titulado "Algunas cuestiones del peronismo" (firmado en diciembre de 1973) los editores colaban, a pura ironía en relación con lo que entendían era una impostura del líder del justicialismo, algunas referencias a los sucesos al otro lado de la cordillera:

Se nos objeta: lo que se trata de evitar es el golpe: el giro a la derecha es una astucia para impedir un zarpazo a la chilena. Ah, sí. Un amigo nuestro decía: antes de morir, prefiero la muerte. Instauremos nosotros la derecha, no sea cosa que venga un gobierno de derecha. Sin contar que no fue precisamente por apoyarse en la izquierda que asesinaron a Allende y están matando a su pueblo, fue por confiar en el "ejército más democrático del continente", por no haber podido darle todo el poder a los trabajadores unos meses antes. Y sin contar, sobre todo, que la caída del propio general Perón sobrevino no cuando este decía "la tierra es para quien la trabaja", sino en 1955, después de haber declarado: "he dejado de ser el presidente de una revolución para ser el presidente de todos los argentinos" (...) [En conclusión] Lo único que impide un golpe de derecha, es la voluntad organizada de la clase obrera. Y la voluntad organizada de la clase obrera exige la revolución. Cuando Eva Perón dijo que el peronismo sería revolucionario o no sería nada, no dijo 'la revolución será peronista o no habrá revolución'. Impuso una orientación, o vaticinó un destino (p. 5).

Como se puede observar, el balance del Chile popular se formulaba ahora en una clave que tendía más a la comparación y a la analogía con la situación argentina que a la pregunta por su singularidad. La vía chilena al socialismo entraba de lleno en la disputa política argentina y su "uso" tomaba la forma de una lección que podía ser utilizada en el debate local. Así, la reflexión sobre sus posibilidades y límites parecía diluirse: la Unidad Popular tal vez había tenido echada sus cartas de antemano y su suerte corroboraba las regularidades inquebrantables de la historia y las leyes de toda revolución.

\footnotetext{
${ }^{18}$ Sobre la lectura del proceso chileno de la UP en revistas vinculadas a la izquierda peronista ver Inés Nercesián, "La izquierda peronista y los gobiernos nacionalistas de la región" en Tortti, María Cristina (directora), op. cit. pp. 189-210.
} 
Un desplazamiento conceptual del mismo tenor, una lectura más ceñida a claves nacionales y un "uso" similar de la cuestión chilena en el debate político local puede también seguirse en Los Libros. La publicación, que luego del alejamiento de Schmucler consolidó su perfil maoísta, ${ }^{19}$ dedicó varias líneas al proceso chileno luego de la caída de Allende. En el editorial del número 32 (octubre-noviembre de 1973), al anunciar un artículo de Antonio Melis que "ajustaba cuentas" con las "deformaciones teóricas y políticas" del guevarismo y sus expresiones en la izquierda europea de matriz antileninista y antimaoísta, se afirmaba que el trabajo (escrito originalmente en 1970) podía ser resignificado a la luz de los acontecimientos recientes:

Depurada de sus desviaciones, la experiencia del Che tiene un centro que hoy más que nunca es necesario subrayar: el énfasis puesto sobre la lucha armada en el marco de una política revolucionaria. El desenlace del proceso chileno lo confirma. El golpe militar en Chile, a la vez que disuelve las ilusiones reformistas de una siempre fracasada vía pacífica al socialismo, destaca la importancia de la cuestión de la estrategia para el poder de América Latina: la consolidación organizativa y política de la resistencia revolucionaria del pueblo chileno empieza a configurar una respuesta concreta a esta cuestión (p. 3).

Convertido en un contra-modelo, la vía chilena al socialismo era leída ahora desde una visión dogmática que encontraba en los acontecimientos la confirmación de supuestos previos. Antes de elaborar ideas para pensar el acontecimiento en aquello que tenía de singular (como se había propuesto en su número especial sobre Chile), Los libros apuntaba ahora exclusivamente a trazar analogías y comparaciones con otras experiencias: Chile se asimilaba a fracasados intentos pasados y a la estrategia "revisionista" promovida por el PCUS a partir de su XX Congreso; reducida al sintagma "vía pacífica", por su propia definición y lógica, la vía chilena al socialismo sólo podía contener entonces la necesidad de su fracaso. Esta línea de lectura sería desplegada con más precisión en el número siguiente (33, enero-febrero 1974) dedicado a revisar los significados y las variantes de la consigna "Liberación o dependencia" en la Argentina. Es sugerente que entre estas cuestiones se colara en la tapa del número el artículo titulado "Chile: vía pacífica al fracaso". Su autor, Mario Toer, caracterizaba a la Unidad Popular como un proyecto "reformista obrero y pequeño burgués" cuyo programa, conducido por una de las superpotencias capitalistas entonces existente, la URSS, había hegemonizado la lucha del pueblo chileno "para desviarlo de la revolución". En la visión de Toer la dirección del PCCh no había sido la receptora pasiva de un espontáneo reformismo producido por la bases, sino la portavoz de un proyecto político en el seno del movimiento obrero "que nucleaba tras sí, en primer lugar, a las variantes socialdemócratas" (p. 31). A diferencia de la actitud asumida en los primeros meses luego del triunfo de Allende, se clausuraba ahora el análisis de la correlación de fuerzas, la búsqueda de estrategias específicas en cada plano de la existencia social y la pregunta por aquello que el proceso chileno podía tener como

\footnotetext{
${ }^{19}$ Luego del alejamiento de Héctor Schmucler de la dirección, promediando 1972, la dirección de la revista quedó en manos de Carlos Altamirano, Beatriz Sarlo y Ricardo Piglia por entonces militantes de organizaciones maoístas.
} 
novedad para las tradiciones del pensamiento y las experiencias revolucionarias. Para el aprendizaje de los pueblos la situación vivida por los chilenos ponía de manifiesto ahora "la perspectiva de derrota que significa no combatir desde un inicio la influencia del revisionismo" y la "reafirmación de los principios elementales del marxismo-leninismo en la teoría de la revolución". ${ }^{20}$ A la luz de lo ocurrido, éstos resultaban "nuevamente incontrastables" (p. 32). ${ }^{21}$ En fin, el desenlace chileno servía en Los Libros para reforzar algunas ideas doctrinales, promover una torsión político-estratégica y legitimar una posición en el debate local: las revoluciones tenían una legalidad inquebrantable y la Argentina (y el peronismo, va de suyo) no tenía por qué escapar al cepillo de acero con el que se peinaba la historia.

\section{Epílogo y una hipótesis final}

Este trabajo forma parte de una investigación de más largo aliento. Presenta una primera aproximación inicial a un corpus de revistas acotado, reunido en función de ciertos denominadores comunes: la coincidencia temporal de su publicación, su pertenencia al espectro de la nueva izquierda intelectual, su perfil como revistas literarias y políticoculturales. En este sentido, las conclusiones presentadas aquí no podrían extenderse al conjunto de la llamada nueva izquierda sin mediar nuevos análisis. Mucho menos debería deducirse de lo expuesto que la presencia del Chile popular en los medios nacionales y su lectura y apropiación desde claves locales fue un tópico exclusivo de esta franja políticocultural. ${ }^{22}$ La descripción y el análisis aquí presentado debería entonces ponerse en relación con un universo mayor. Esta mirada permitiría reconstruir un mapa más amplio del campo de significaciones aquí trabajado y de sus modulaciones. ${ }^{23}$ Aun su carácter parcial, lo expuesto hasta aquí nos permite esbozar algunas conclusiones.

\footnotetext{
${ }^{20}$ Según Toer estos principios eran los siguientes: necesidad de construir una fuerza propia que se delimitara de cualquier variante reformista o alianza de clase; la necesidad de organizar y armar al pueblo; la concepción del Estado como órgano de clase, instrumento de dominación y represión (este era el elemento crucial que dividía a reformistas y revolucionarios, señalaba) y la consecuente necesidad de destruirlo y reemplazarlo por otro fundado en "el pueblo en armas" (p. 32). Y, por cierto, "el principio básico del marxismo": que al mundo no se lo contempla, sino que hay que transformarlo (p. 33).

${ }^{21}$ Algunos meses después (número 37 de septiembre-octubre de 1974) Toer desplegaría argumentos en la misma línea en su reseña de La lucha de clases en Chile (1974) de Manuel Castells.

${ }^{22}$ La lectura de un periódico como La Opinión (1971-1977) da cuenta de la fuerte presencia de la cuestión chilena en el debate político-cultural argentino y de la forma en que interpeló a toda una franja intelectual, no sólo en función de la discusión político-estratégica sino en su misma existencia en tanto figura social. En La Opinión se hace visible con nitidez el doble prisma con el que diversos sectores intelectuales y políticos se aproximaron al proceso chileno: el de la revolución cubana primero (esta clave se acentuaría a partir de la caída de Allende y del ejercicio de una lectura en clave heroica, paradójicamente guevarista, de su figura y de su muerte "en combate") y luego el de las alternativas en torno a Perón y la relación con la tendencia revolucionaria de su movimiento. Sobre la lectura del proceso chileno en revistas vinculadas a la izquierda peronista, ver Nercesián, Inés, op. cit.

${ }^{23}$ El proceso chileno 1970-1973, en algunos de sus avatares y dimensiones, ocupó también con mayor o menor intensidad las páginas de otra serie de revistas del espectro de la nueva izquierda intelectual: publicaciones político-culturales (Pasado y Presente, segunda época, 1973); literarias (Crisis, 1973-1976), de
} 
En primer lugar, una constatación: en las publicaciones analizadas la vía chilena al socialismo tuvo una presencia que, si bien fue secundaria en relación con otras cuestiones, no dejó de ser destacada. En segundo lugar, hemos propuesto una interpretación de los usos o modalidades que tomó esta presencia: en El Escarabajo de Oro, en Nuevos Aires y en Los Libros, quienes se involucraron en la discusión sobre las alternativas y límites de la experiencia chilena lo hicieron desde posiciones diversas: como ocurrió con Cuba, aunque en menor escala y durante un tiempo más breve, a través de Chile, o mejor, de los límites y posibilidades que se atribuían a la vía chilena al socialismo, una franja de intelectuales discutió la Argentina y debatió sobre estrategias político-culturales; incluso encontró en los acontecimientos del país trasandino un espejo donde justificar o delinear una figura intelectual y ensayar formas de expresión y ejercicio. En Los Libros y en El Escarabajo de Oro la experiencia de la Unidad Popular se leyó en una primera etapa desde una equilibrada combinación de cautela y expectativa mediada por el prisma de la revolución cubana. Esta paradojal combinación permitía una evaluación abierta del proceso, una mixtura posible de ambos caminos - reforma y revolución - que por entonces lejos estaban de mostrarse incompatibles. ${ }^{24}$ En este punto, se habilitaba a pensar aquello que la experiencia chilena podía tener de inédito y de novedad para la tradición de la izquierda y el pensamiento marxista. La revista Nuevos Aires también se vio interpelada a posicionarse sobre los acontecimientos que se sucedían al otro lado de la cordillera. Lo hizo de entrada desde una impronta doctrinaria según la cual el proceso chileno debía medirse en función de supuestos ya fijados. La intervención, como vimos, tenía como objeto y destinatario a la intelectualidad argentina y debe leerse en su dualidad constitutiva: como una toma de posición en el campo intelectual a la vez que en el campo de la literatura; de allí que cobre significación si se la coloca en serie con el conjunto de las publicaciones afines. Finalmente, El Escarabajo de Oro y Los Libros volvieron sobre sus pasos luego del golpe militar de 1973. El ascenso y la caída de Allende se leyó entonces desde nuevas coordenadas: restablecido el juego de la democracia institucional en la Argentina y en plena agudización de las tensiones que se jugaban al interior de un peronismo ya en el poder, la experiencia chilena debía significarse como una "lección" contra tentativas "reformistas" afines en el país. Desde esta visión, la UP había dejado desarmado al pueblo frente a las fuerzas de la reacción que su propia política había desatado. ${ }^{25}$

Lo expuesto, en suma, permite evaluar la presencia de la cuestión chilena en el espectro de una franja intelectual de la nueva izquierda argentina y el modo en que Chile fue un "uso" dispuesto desde una escena local, esto es, un medio y una oportunidad para intervenir sobre querellas teórico-políticas clásicas de la tradición de izquierda, legitimar

ciencias sociales (Comunicación y Cultura, 1973-1985; Lenguajes, 1974-1980, Envido, 1970-1973), entre otras.

${ }^{24}$ Tanto Allende como Fidel Castro — quien visitó en 1971 Chile durante casi un mes — habilitaban esta combinación o lectura no excluyente. Su promotor intelectual más destacado, con amplia circulación de sus escritos en editoriales y medios locales fue Regis Debray. Ver Regis Debray, Conversación con Allende, Buenos Aires, Siglo XXI, 1971.

${ }^{25}$ Otros sectores políticos e intelectuales, aunque no estuviera en nuestros objetivos presentarlos aquí, encontraron en los acontecimientos de Chile una "lección" inversa: contra el "infantilismo de la ultra izquierda" que había contribuido en su intransigencia a debilitar al gobierno de Allende. 
proyectos culturales $y$, por último, posicionarse sobre la coyuntura. Pero tal vez este recorrido alcance plena significación si se recupera uno de los interrogantes enunciados al inicio de este trabajo, en torno a los motivos de la ausencia de consideraciones sobre el influjo del Chile popular en los testimonios y reconstrucciones canónicas que tematizaron la emergencia de la nueva izquierda intelectual argentina en el período. ${ }^{26}$ Sobre este punto y a la luz de lo expuesto, apenas podemos sugerir aquí algunas hipótesis. Por un lado, esta ausencia en los balances formulados a partir de los años ochenta puede comprenderse por la ilegibilidad que luego del golpe de 1973 tomó para una zona de la nueva izquierda la vía chilena al socialismo. La lectura dogmática que circuló en franjas importantes de este medio intelectual — haciendo aquí abstracción de las condiciones en las que se promovió y que permiten comprenderla - tendió a confirmar supuestos previos más que a producir ideas nuevas a partir de lo acontecido. La imagen en la que el proyecto de la Unidad Popular no representaba más que una vía destinada al fracaso tomó fuerza y produjo condiciones para la invisibilización futura de los alcances de esta tentativa y de su fuerte presencia y significación en el debate local. ${ }^{27}$ Paradójicamente, muchos de los núcleos intelectuales para los que la vía chilena al socialismo había supuesto un modo ingenuo de anudar socialismo y democracia, en los años ochenta promovieron, desde posiciones de prestigio e influencia cultural, balances en los que leyeron el período anterior y revisitaron el tópico desde una clave — si se me permiten la simplificación y el anacronismosocialdemócrata-liberal $^{28}$, desde la cual el Chile de Allende no podía sino resultar demasiado radical. Tal vez en esta superposición de lecturas y temporalidades se encuentre la clave para interpretar la ausencia de la cuestión chilena en los testimonios y balances historiográficos canónicos de los debates y querellas de la nueva izquierda intelectual argentina de los años sesenta y setenta.

\section{Bibliografía}

- Altamirano, Carlos, Peronismo y cultura de izquierda, Buenos Aires, Siglo XXI, 2011 [2001].

- Aricó, José, La cola del diablo. Itinerario de Gramsci en América Latina, Buenos Aires, Siglo XXI, 2005 [1988].

- Calabrese, Elisa, "Las revistas de Abelardo Castillo. Un proyecto cultural alternativo", en Revista CELEHIS. Tomo monográfico: Revista sobre revistas, año 14/15, n 17, 2005/2006, pp. 39-58.

- Debray, Regis, Conversación con Allende, Buenos Aires, Siglo XXI, 1971.

- de Diego, José Luis, ¿Quién de Nosotros escribirá el Facundo? Intelectuales y escritores en Argentina (1970-1986), La Plata, ediciones Al Margen, 2007 [2004].

\footnotetext{
${ }^{26}$ Ver la nota 1 de este artículo y sobre las nuevas perspectivas renovadoras las notas 2 y 3 .

${ }^{27}$ Se trataba de una significación en disputa: durante los meses que siguieron a la caída de Allende se publicaron decenas de libros sobre la experiencia chilena en emprendimientos editoriales vinculados a este universo intelectual: Siglo XXI, Tiempo Contemporáneo, Ediciones de Crisis, entre otros.

${ }^{28}$ Para un balance en esta clave desde la teoría política véase Freibrun, Nicolás, La reinvención de la democracia. Intelectuales e ideas políticas en la Argentina de los ochenta, Buenos Aires, Imago Mundi, 2014.
} 
- Freibrun, Nicolás, La reinvención de la democracia. Intelectuales e ideas políticas en la Argentina de los ochenta, Buenos Aires, Imago Mundi, 2014.

- Gilman, Claudia, Entre la pluma y el fusil, Buenos Aires, Siglo XXI, 2004

- Nercesián, Inés, "La izquierda peronista y los gobiernos nacionalistas de la región" en Tortti, María Cristina (directora), Chama, Mauricio, Celentano Adrián (co-directores), La nueva izquierda argentina (1955-1976). Socialismo, peronismo y revolución, Rosario, Prohistoria, 2014, pp. 189210.

"Chile durante los años setenta. Reforma o revolución. El MIR y la lectura de la situación latinoamericana", en Waldo Ansaldi, Verónica Giordano (eds.), América Latina. Tiempo de violencias, Buenos Aires, Ariel, 2014.

- Panesi, Jorge, "La crítica argentina y el discurso de la dependencia", en Críticas, Buenos Aires, Norma, 2000 [1998], pp. 17-45 [publicado originalmente en Filología, año XX, 1, 1985].

- Sarlo, Beatriz, La batalla de las ideas (1943-1973), Buenos Aires, Emecé, 2007 [2001]

- Sigal, Silvia, Intelectuales y poder en la década del sesenta, Buenos Aires, Punto Sur, 1991.

- Terán, Oscar, Nuestros años sesenta, Buenos Aires, Siglo XXI, 2013 [1991]

- Tortti, María Cristina, "La nueva izquierda argentina. La cuestión del peronismo y el tema de la revolución", en Tortti, María Cristina (directora), Chama, Mauricio, Celentano Adrián (codirectores), La nueva izquierda argentina (1955-1976). Socialismo, peronismo y revolución, Rosario, Prohistoria, 2014.

- Zarowsky, Mariano, Del laboratorio chileno a la comunicación-mundo. Un itinerario intelectual de Armand Mattelart, Buenos Aires, Biblos, 2013

"De Los Libros a Comunicación y cultura. Praxis editorialista y proyecto intelectual en el itinerario de Héctor Schmucler”, en La trama de la Comunicación, Vol. 20, N¹, 2016.

\section{Revistas}

El Escarabajo de Oro

Los Libros

Nuevos Aires 